\section{Epicritic Pain}

Kerry Donnelly

VA WNY Healthcare System, University of Buffalo (SUNY) Behavioral Health Careline (116B), Buffalo, NY, USA

\section{Definition}

A variant of nociceptive pain (pain resulting from ongoing activation of primary afferent neurons by noxious stimuli), epicritic pain is transmitted to the spinal cord by A Delta $(\delta)$ fibers. These fibers are sparsely myelinated, large-diameter, and fast- conducting, which transmit sharp, well-localized pain. A $\delta$ fibers are mostly sensitive to mechanical and thermal stimuli. Epicritic pain is less responsive to opioid therapy than is protopathic pain.

\section{Cross-References}

Protopathic Pain

\section{References and Readings}

McCaffery, M., \& Pasero, C. (1999). Pain clinical manual (2nd ed.). St. Louis: Mosby. 